EDITORIAL

\title{
More than Meets the Eyes in Focal Epilepsy
}

Can. J. Neurol. Sci. 2009; 36: 542

In this issue of the Journal, Sarnat and Sarnat ${ }^{1}$ report on a case-control study of alpha-B-crystallin (CRYAB) immunocytochemistry in 45 surgically resected brain specimens and two post-mortem brains of epileptic children, compared to normal controls. Alpha-B-crystallin was mostly over-expressed in glial cells, including both astrocytes and oligodendrocytes. Perineuronal glia as well as occasional neuronal immunolabelling by CRYAB were also documented. In six cases, reactivity was most intense at or near epileptic foci. The above findings were unrelated to co-morbid lesions, were they dysembryoplastic neuroepithelial tumors, tuberous sclerosis, or cortical dysplasia. In 20 control fetal brains, no CRYAB immuno-reactivity was observed.

Alpha-B-crystallin is a cell 'stress'-induced protein which belongs to small size heat shock proteins (HSP), such as HSP27. It is particularly prone to be up-regulated in a pathophysiological setting in which de-natured or mutated proteins are at risk of becoming misfolded or transformed into inclusion bodies. Its role is then to promote shuttling of abnormal proteins into the proteosome by ubiquitination.

Delayed induction of CRYAB in kainic acid treated mice brains was observed in CA3 sectors of hippocampi in association with severe neuronal loss after repeated seizures, with Nitric Oxyde Synthase (NOS) up-regulation ${ }^{2}$. However, phosphorylated isoforms of CRYAB and HSP27 were observed in the human myocardium after cardioplegia and cardiopulmonary bypass ${ }^{3}$, and thus appeared to be quite sensitive to anoxic-ischemic conditions. CRYAB up-regulation was reported in a wide array of stressfull settings for brain cells, in human as well as in several experimental animal models ${ }^{4}$. It was also associated with reactive gliosis, a pathologic hallmark of chronic human epilepsy. The CRYAB and HSP27 levels were frequently documented as increased and ubiquitinated ${ }^{4}$, which may be readily observed by IHC methods within Rosenthal fibers ${ }^{5}$, a type of glial inclusion body ${ }^{6}$. In mice in which alpha-B-crystallin and other small HSP's were knocked out, myocardial cells displayed necrosis and apoptosis ${ }^{7}$. Mutations specifically localized to the gene locus of CRYAB cause inherited myofibrillar myopathy ${ }^{8}$.

These results suggest that CRYAB immunolabelling provides a more reliable method of mapping epileptic foci in resected brain tissues than GFAP immunostaining or neuronal markers. More investigations are needed to confirm the above data in larger cohorts of epileptic patients treated by surgery and determine to what extent the anoxic-ischemic conditions frequently recorded during seizures contribute to CRYAB upregulation, which small HSP's tend to play a role in this process, and to what extent NOS in up-stream molecular cascades may also be involved.

\section{REFERENCES}

Montreal, Quebec

1. Sarnat HB, Flores-Sarnat L. $\alpha$-B-crystallin as a tissue marker of epileptic foci in paediatric resections. Can J Neurol Sci. 2009; 36: 566-74.

2. Che Y, Piao CS, Han PL, Lee JK. Delayed induction of alpha-Bcrystallin in activated glia cells of hippocampus in kainic acidtreated mouse brain. J Neurosc Res. 2001; 65 (5): 425-31.

3. Clements RT, Sodha NR, Feng J, Mieno S, Boodhwani M, Ramlawi $\mathrm{B}$, et al. Phosphorylation and translocation of heat shock protein 27 and alpha-B-crystallin in human myocardium after cardioplegia and cardiopulmonary bypass. J Thorac Cardiovasc Surg. 2007; 134 (6): 1461-70.

4. Goldman JE, Corbin E. Rosenthal fibers contain ubiquitinated apha-B-crystallin. Am J Pathol. 1991; 139 (4): 933-8.

5. Iwaki T, Iwaki A, Tateishi J, Sakaki Y, Goldman JE. Alpha-Bcrystallin and $27-\mathrm{kd}$ heat shock protein are regulated by stress conditions in the central nervous system and accumulate in Rosenthal fibers. Am J Pathol. 1993; 143 (2): 487-95.

6. Head MW, Goldman JE. Small heat shock proteins, the cytoskeleton, and inclusion body formation. Neuropathol Applied Neurobiol. 2000; 26 (4): 304-12.

7. Morrison LE, Whittaker RJ, Klepper RE, Wawrousek EF, Glembotski CC. Roles for alpha-B-crystallin and HSPB2 in protecting the myocardium from ischemia-reperfusion-induced damage in a KO mouse model. Am J Physiol Heart Circ Physiol. 2004; 286 (3): H847-855. Epub 2003 Oct 30.

8. Simon S, Fontaine JM, Martin JL, Sun X, Hoppe AD, Welsh MJ, et al. Myopathy-associated alpha-B-crystallin mutants: abnormal phosphorylation, intracellular location, and interactions with other small heat shock proteins. J Biol Chem. 2007; 282 (47): 34276-87. Epub 2007 Sep 25. 